\title{
Differences in Time Course of ACh and GABA Modulation of Excitatory Synaptic Potentials in Slices of Rat Hippocampus
}

\author{
MICHAEL E. HASSELMO AND BRIAN P. FEHLAU \\ Department of Psychology, Program in Neuroscience and Center for BioDynamics, Boston University, \\ Boston, Massachusetts 02215
}

Received 6 September 2000; accepted in final form 25 June 2001

\begin{abstract}
Hasselmo, Michael E. and Brian P. Fehlau. Differences in time course of ACh and GABA modulation of excitatory synaptic potentials in slices of rat hippocampus. J Neurophysiol 86: 1792-1802, 2001. Activation of muscarinic receptors and $\mathrm{GABA}_{\mathrm{B}}$ receptors causes presynaptic inhibition of glutamatergic synaptic potentials at excitatory feedback connections in cortical structures. These effects may regulate dynamics in cortical structures, with presynaptic inhibition allowing extrinsic afferent input to dominate during encoding, while the absence of presynaptic inhibition allows stronger excitatory feedback during retrieval or consolidation. However, proposals for a functional role of such modulatory effects strongly depend on the time course of these modulatory effects; how rapidly can they turn off and on? In brain slice preparations of hippocampal region CA1, we have explored the time course of suppression of extracellularly recorded synaptic potentials after pressure pulse application of acetylcholine and GABA. Acetylcholine causes suppression of extracellular potentials with onset time constants between 1 and $2 \mathrm{~s}$, and decay constants ranging between 10 and $20 \mathrm{~s}$, even with very brief injection pulses. GABA causes suppression of extracellular potentials with onset time constants between 0.2 and $0.7 \mathrm{~s}$, and decay time constants that decrease to values shorter than $2 \mathrm{~s}$ for very brief injection pulses. These techniques do not give an exact measure of the physiological time course in vivo, but they give a notion of the relative time course of the two modulators. The slow changes due to activation of muscarinic acetylcholine receptors may alter the dynamics of cortical circuits over longer intervals (e.g., between different stages of waking and sleep), setting dynamics appropriate for encoding versus consolidation processes. The faster changes in synaptic potentials caused by GABA could cause changes within each cycle of the theta rhythm, rapidly switching between encoding and retrieval dynamics during exploration.
\end{abstract}

\section{IN T R O D U C T I O N}

The hippocampus receives innervation from both cholinergic and GABAergic neurons in the medial septum (see review in Stewart and Fox 1990). Neurons in the medial septum show phasic firing relative to the hippocampal theta rhythm, a prominent electroencephalogram (EEG) oscillation of 3-10 Hz recorded from the hippocampus in rats (Bland and Colom 1993; Stewart and Fox 1990). Intracellular recording suggests that cholinergic neurons in medial septum tend to fire on the positive phase of theta recorded at the hippocampal fissure, whereas GABAergic neurons in medial septum fire on the negative phase of theta (Brazhnik and Fox 1997, 1999). These

\footnotetext{
Address for reprint requests: M. E. Hasselmo, Dept. of Psychology, Boston University, 64 Cummington St., Boston, MA 02215 (E-mail: hasselmo@bu.edu).
}

firing patterns suggest that a function of theta rhythm could be to provide phasic changes in cholinergic and GABAergic modulatory effects within the hippocampus. However, phasic changes in modulatory state would require modulatory effects that are sufficiently rapid to increase and decrease within the time course of a single theta cycle (100-300 ms).

What types of modulatory effects could be induced by cholinergic and GABAergic innervation? Activation of both presynaptic muscarinic acetylcholine receptors and presynaptic $\mathrm{GABA}_{\mathrm{B}}$ receptors has been shown to suppress glutamatergic synaptic transmission at excitatory feedback connections in cortical structures. Activation of muscarinic acetylcholine receptors causes presynaptic inhibition of excitatory synaptic potentials in hippocampal region CA1 (Hasselmo and Schnell 1994; Herreras et al. 1988; Hounsgaard 1978; Valentino and Dingledine 1981), region CA3 (Hasselmo et al. 1995), the dentate gyrus (Kahle and Cotman 1989; Yamamoto and Kawai 1967), piriform cortex (Hasselmo and Bower 1992; Williams and Constanti 1988), and neocortical subregions (Brocher et al. 1992; Hasselmo and Cekic 1996). This selective presynaptic inhibition of intrinsic and feedback connections has been proposed to set appropriate dynamics for encoding of new information, preventing retrieval of previously stored information at feedback synapses from interfering with storage of new information about sensory input arriving via afferent synapses (Hasselmo 1995; Hasselmo et al. 1995). Removal of the suppression of feedback synapses would set appropriate dynamics for retrieval mediated by these synapses (Hasselmo 1995; Hasselmo and Bower 1992; Hasselmo et al. 1995). Transitions between encoding with strong afferent transmission and retrieval with strong feedback transmission would require relatively rapid changes in modulation, as normal behavior requires encoding and retrieval to occur frequently within a short period of time. As an alternative, cholinergic modulation of transmission could also contribute to longer term changes between an encoding state and a consolidation state during which excitatory feedback from the hippocampus to the entorhinal cortex and other cortical regions is stronger than during retrieval and can drive synaptic modification in neocortical structures (Buzsaki 1989; Hasselmo 1999; Hasselmo et al. 1996; Wilson and McNaughton 1993). Transitions between encoding and consolidation only require relatively slow

\footnotetext{
The costs of publication of this article were defrayed in part by the payment of page charges. The article must therefore be hereby marked "advertisement" in accordance with 18 U.S.C. Section 1734 solely to indicate this fact.
} 
changes in modulatory state, as consolidation only needs to occur at intervals of minutes to hours.

Are the modulatory effects of acetylcholine sufficiently rapid to change within a theta cycle? The time course of muscarinic modulation of glutamatergic synaptic transmission has not been described extensively. Most experiments on modulation of transmission utilize bath application of the agonist carbachol, which is not sensitive to breakdown by acetylcholinesterase. This provides appropriate data for construction of dose response curves, but does not provide information about the time course of the modulatory effect. The time course of another modulatory effect of muscarinic receptor activation has been described. Stimulation of endogenous acetylcholine release in slice preparations causes a slow postsynaptic depolarization (Benardo 1993; Benardo and Prince 1982; Cole and Nicoll 1984) that increases over a few seconds and decreases over 10-20 s. This effect is blocked by muscarinic antagonists such as atropine. Because of these data, many researchers assume that the time course of muscarinic receptor effects is uniformly slow. However, some in vivo experiments indirectly suggest that the muscarinic modulation of evoked synaptic potentials might undergo relatively rapid changes (Linster et al. 1999). Here we use brief pressure pulse applications of acetylcholine in slice preparations to analyze the time course of cholinergic modulation of excitatory synaptic transmission.

In addition to the phasic changes in cholinergic modulation, septal input causes inhibitory interneurons in hippocampal region CA1 to show phasic changes in firing within each theta cycle (Toth et al. 1997). In urethan-anesthetized rats, interneurons fire most at the nadir of the theta cycle measured in the EEG at the hippocampal fissure (Buzsaki and Eidelberg 1983; Fox et al. 1986). In walking rats, interneurons fire most at about $50^{\circ}$ before the peak EEG in the dentate gyrus (Fox et al. 1986; Skaggs et al. 1996). This phasic firing provides the potential for phasic changes in GABA levels within a theta cycle. Changes in GABA levels could cause a number of effects on the circuit properties of the network, including changes in membrane potential, excitatory and inhibitory synaptic transmission, and long-term potentiation (see Mott and Lewis 1994, for review). Among other things, activation of $\mathrm{GABA}_{\mathrm{B}}$ heteroreceptors on glutamate presynaptic terminals has been shown to regulate glutamatergic synaptic transmission. The $\mathrm{GABA}_{\mathrm{B}}$ agonist baclofen has been shown to selectively suppress intrinsic but not afferent excitatory synaptic transmission in the hippocampus (Ault and Nadler 1982; Colbert and Levy 1992) and piriform cortex (Tang and Hasselmo 1994). If this modulation is rapid, it may provide a means for dramatic changes in the relative strength of excitatory afferent input versus excitatory feedback transmission across different phases of a single theta cycle.

The techniques used here will not explicitly determine the time course of muscarinic and GABA effects in vivo, but they provide a means for comparing the relative time course of muscarinic and GABA receptor effects on excitatory synaptic transmission in the hippocampus.

\section{METHODS}

Brain slices were prepared from female albino Sprague-Dawley rats (Charles River Breeders), 6-10 wk of age. The rats were anesthetized using halothane and immediately decapitated. The brains were ex- tracted and placed in a chilled, oxygenated solution of artificial cerebrospinal fluid (ACSF). The ACSF had the following concentrations (in mM): $26 \mathrm{NaHCO}_{3}, 124 \mathrm{NaCl}, 2.5 \mathrm{KCl}, 1.2 \mathrm{KH}_{2} \mathrm{PO}_{4}, 2.4$ $\mathrm{CaCl}_{2}, 1.3 \mathrm{MgSO}_{4}$, and 10 glucose. The two hippocampi from each brain were surgically removed. Each hippocampus was then sliced transverse to the septotemporal axis using a vibratome into slices of approximately $400 \mu \mathrm{m}$ in thickness. These slices were transferred to and stored in a new solution of ACSF at room temperature, with a mixture of $95 \% \mathrm{O}_{2}-5 \% \mathrm{CO}_{2}$ constantly bubbling through the solution.

Before any experiments were performed, the slices were allowed to adjust to the solution for at least $1 \mathrm{~h}$ after surgery. For experiments, the slices were placed on a nylon grid, in a standard submersion-type slice chamber. Oxygenated ACSF, at a temperature of $36^{\circ} \mathrm{C}\left( \pm 1^{\circ} \mathrm{C}\right)$ was constantly perfused through the chamber (at a rate of $\sim 4 \mathrm{ml} / \mathrm{min}$ ). A saturated $\mathrm{O}_{2}$ environment was maintained over the slice by passing $\mathrm{O}_{2}$ over the top of perfusion chamber. The slices were illuminated from below to allow for better visualization of the fiber and cell-body layers and for better placement of electrodes.

Bipolar stimulating electrodes (from Frederick Haer \& Co.) were used to administer current to the slices. The electrodes consisted of twisted strands of Teflon-insulated 0.002-in.-diam platinum-iridium wire, and only the tips of the wire were without insulation. Occasionally, noninsulated monopolar electrodes (from Microprobe, 1.3-1.7 $\mathrm{M} \Omega$ ) were also used. Insulated electrodes can be used to prevent current spreading, but for this experiment, current spreading was not identified as a problem. The stimulating electrodes send current pulses on the order of $10-250 \mu \mathrm{A}$ for $100 \mu \mathrm{s}$.

Stimulus pulses were delivered by a Neurodata SIU 90, isolated current source. The amplitude of the current could be adjusted using this piece of equipment. This current source was connected to a Neurodata PG4000 Digital Stimulator, which controlled both the stimulus duration $(100 \mu \mathrm{s})$ and the time at which the stimulus was administered. The recording electrode was connected to an A-M systems Microelectrode Amplifier (amplification set to 1000 times). The amplified signal was sent to a BK Precision 2522A oscilloscope and to an A/D conversion board where the signals were digitized and recorded on a Gateway 2000 386SX computer using a modified custom-written software program (ICEPAC, by M. Wilson, Caltech). The current was delivered $20 \mathrm{~ms}$ after the digital stimulator triggered an oscilloscope sweep. The recording software also registered the beginning of a trial at the time of oscilloscope triggering.

Figure 1 illustrates the placement of the recording and stimulating electrodes in region $\mathrm{CA} 1$ and the dentate gyrus. In region $\mathrm{CA} 1$, the stimulating electrode delivered current to the Schaffer collateral fibers, which run from region $\mathrm{CA} 3$ to this region, synapsing in stratum radiatum. The recording electrode measured a field potential in stratum radiatum. In the dentate gyrus, the stimulating electrode delivered current to the perforant path fibers entering the hippocampus from the entorhinal cortex. These fibers synapse in stratum moleculare in the dentate, which is where the recording electrode was placed. A set of electrodes was placed in either region CA1 or the dentate gyrus at one time, although often experiments were performed sequentially in the two different areas of the hippocampus within the same brain slice. The desired range for potential size (height from baseline to trough) was $0.5-1.5 \mathrm{mV}$. Examples of field potentials are shown in Figs. 2 and 6.

Initial experiments attempted to obtain modulation of synaptic potentials through stimulation of endogenous release of acetylcholine. This technique has been used to study the slow cholinergic depolarization of pyramidal cell membrane potential (Benardo and Prince 1982; Cole and Nicoll 1984). However, multiple experiments attempting to elicit decreases in synaptic potential amplitude due to stimulation of endogenous acetylcholine release were not successful in obtaining suppression of field potentials. Therefore we focused on recording the time course of effect of pressure pulse application of neuromodulatory substances.

Pressure pulse application provided an effective means of deliver- 


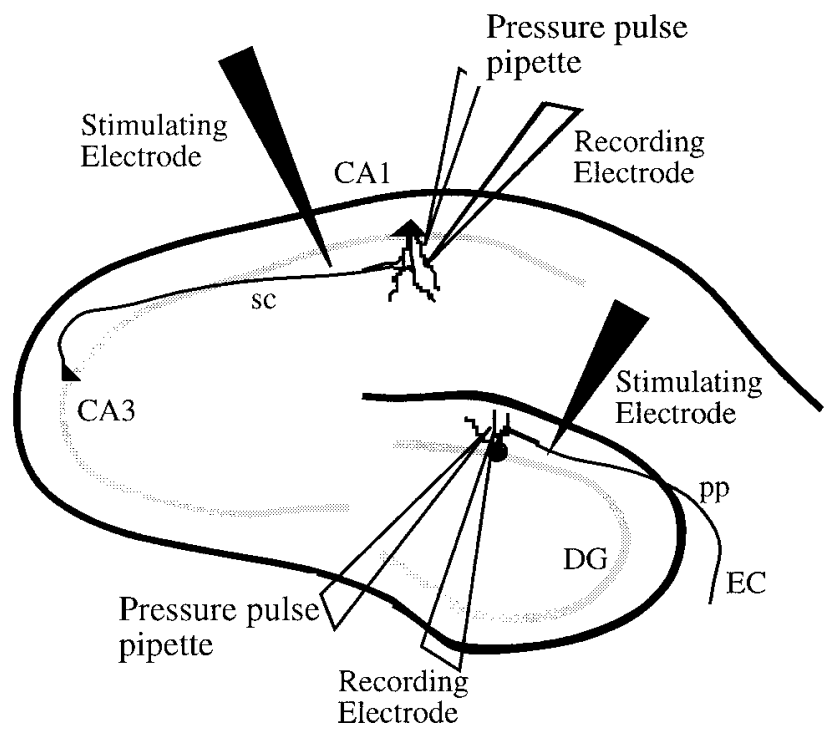

FIG. 1. Location of stimulating, recording, and pressure pulse electrodes in brain slice preparations of the hippocampal formation. For experiments on region CA1, stimulating electrodes were placed in stratum radiatum between region $\mathrm{CA} 3$ and region $\mathrm{CA} 1$, recording electrodes were placed in stratum radiatum of region $\mathrm{CA} 1$, and the pressure pulse pipettes were placed as close to the recording electrode as possible. For experiments on the dentate gyrus (DG), stimulating and recording electrodes were placed in stratum moleculare with pressure pulse pipettes placed as close as possible to the recording electrode without disrupting the recording of potentials. sc, Schaffer collaterals; pp, perforant path; EC, entorhinal cortex.

ing modulatory substances to the recording site. Each experiment involved a local ejection of a solution of ACSF containing the modulatory agent from a glass micropipette, which was different from the recording pipette (which had smaller tips). This ejection was accomplished using a multi-channel Picospritzer (General Valve). The Picospritzer provided a pulse of gas pressure (either $\mathrm{N}_{2}$ or compressed air) to eject the substance from the glass micropipette. An air pressure of 10 p.s.i. was used for all experiments. The Neurodata digital stimulator also triggered the Picospritzer, and the length of the ejection was directly proportional to the amount of liquid that was released. In addition, there was an 8-ms delay from the time of triggering to the initiation of release of liquid from the pipette. Viewed under a microscope, individual pipettes utilized on different days released very similar volumes of fluid in response to a 10 -ms pressure pulse.

The pressure pulse pipettes were placed as close to the recording electrode as possible. This method would assure that the substances were released only in the area being studied. As a default time delay, pressure pulse injections were set to be $500 \mathrm{~ms}$ out of phase with the electrical stimulation inducing synaptic potentials. Thus the first synaptic potential recorded after pressure pulse injection was at a delay of $500 \mathrm{~ms}$ unless otherwise specified. This initial delay was manipulated for GABA application to obtain more accurate measurements of the rapid onset of modulation.

Before an experiment was performed, the field potential was determined to be stable for a minimum of $5 \mathrm{~min}$. A test solution pipette was then put in position. A trial ejection of solution was performed to assure that the test solution was producing the desired effect (suppression, in most cases). If the trial ejection was successful, an experimental trial was begun. An experiment entailed the following procedure: 1) field potentials were measured at $1 \mathrm{~Hz}, 2$ ) at least 20 control potentials were recorded before the test solution was ejected, 3 ) the test solution was ejected at a specified time, and 4) the potential was measured at the same rate either for a specific amount of time or until the potential had recovered fully. The trial length ranged between 75 and 400 s (75-400 potentials recorded).

Appropriate concentrations of specific test substances in solution were determined experimentally. The various drugs that were used in this experiment include (with concentrations listed in $\mathrm{mM}$ ): acetylcholine (10), GABA (5-10), baclofen (1), bicuculline (5), phaclofen (1-10), atropine (1), and carbachol (10). Note that these concentrations are much higher than in bath applications (described in next paragraph) because only small amounts were ejected locally during each experiment. All drugs were ordered from Sigma. When more than one substance was used, two pressure pulse glass micropipettes were used. Both pipettes were placed very near to the recording electrode, as discussed above. In many slices, the effects of different durations of pressure pulse injections were measured. For some slices many different trials were run, but only one primary drug (acetylcholine, carbachol, GABA, or baclofen) was used on each slice.

In addition to ejecting drugs from the pressure pulse pipette, test substances were also placed in the solution of ACSF that constantly flows through the slice chamber ("bath perfusion"). Using this method, one drug was first ejected from the pressure pulse pipette, in normal ACSF, and the effect of this substance was noted. Then, ACSF containing a different substance (an antagonist substance) would be cycled through the perfusion chamber. Another pressure pulse ejection trial was performed in the new ACSF to determine whether the effect changed as a result of the presence of the second drug in the ACSF solution. The purpose of this type of experiment was to more accurately administer antagonists (atropine, bicuculline, and phaclofen) at specific concentrations. The following drug perfusion protocols were performed: 1) acetylcholine pressure pulse, atropine (5 $\mu \mathrm{M})$ in bath; 2) GABA pressure pulse, bicuculline $(10 \mu \mathrm{M})$ in bath; and 3) GABA pressure pulse, phaclofen $(10-100 \mu \mathrm{M})$ in bath. Bath application was initiated $1 / 2 \mathrm{~h}$ before performance of experiments, to ensure the presence of the dissolved antagonist drug in the perfusion chamber.

\section{Measurement of amplitude changes}

A computer program was used to measure the amplitude of synaptic field potentials recorded during each experiment. Examples of field potentials are shown in Fig. 2, and measurements of amplitude are shown in Fig. 3. Each recording consisted of three components. First, a transient stimulus artifact occurred at the time of delivery of current (seen as a vertical downward line in Fig. 2). Second, a transient negative

\section{A ACh application in region CA1}

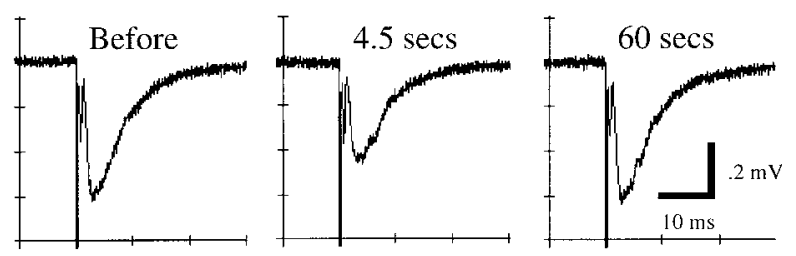

\section{B ACh application in dentate gyrus}

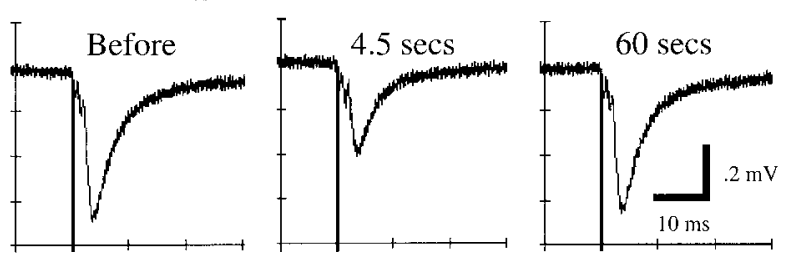

FIG. 2. A: example of the effect of pressure pulse application of acetylcholine on synaptic potentials recorded in stratum radiatum of hippocampal region CA1. Potentials are shown before injection, $4.5 \mathrm{~s}$ after pressure pulse application of acetylcholine, and $60 \mathrm{~s}$ after pressure pulse application of acetylcholine. $B$ : effect of pressure pulse application of acetylcholine on synaptic potentials recorded in stratum moleculare of the dentate gyrus before application, $4.5 \mathrm{~s}$ after application, and $60 \mathrm{~s}$ after application. 
deflection occurred in the recordings. This deflection is termed a "fiber potential," and it is caused by action potentials propagating down fibers in the area of the recording electrode. The third component of the recording is the excitatory synaptic field potential itself, which appeared as a larger, less transient, negative deflection.

The computer program measured the difference between the voltage at the time when the synaptic field potential reached its maximum negativity, and the voltage at a time before the pulse delivered through the stimulating electrode (baseline). This was plotted as the amplitude of synaptic potential. In the time course plots, the amplitude of synaptic potentials are always plotted as percentage of control ampli-

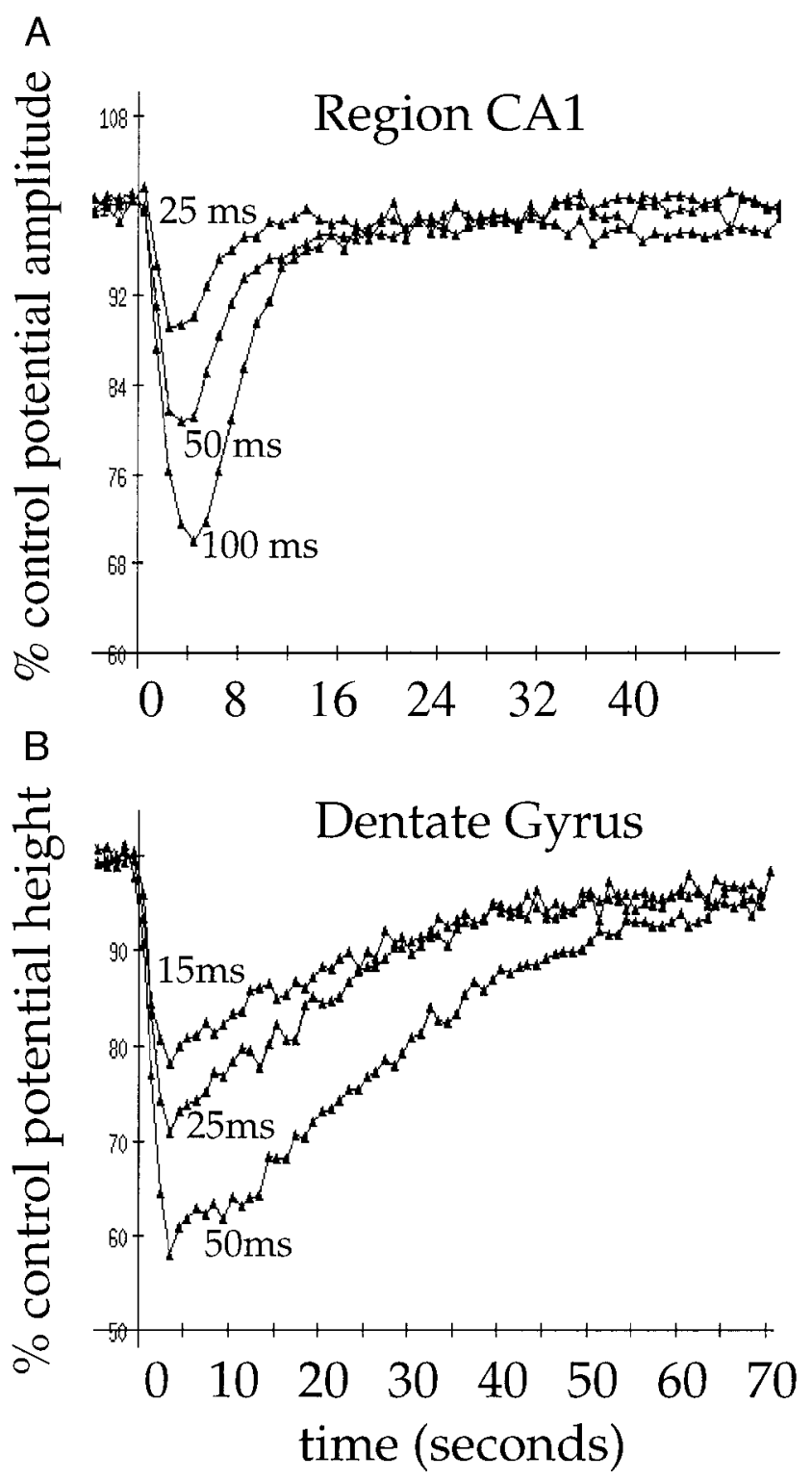

FIG. 3. Amplitude measurements for synaptic potentials recorded at 1-s intervals $(1 \mathrm{~Hz})$ before and after pressure pulse applications of acetylcholine. $A$ : time course of change in amplitude of synaptic potentials shown for pressure pulse applications of acetylcholine in hippocampal region CA1. Three different durations of pressure pulse were used $(100,50$, and $25 \mathrm{~ms})$. Five baseline measurements are shown before pressure-pulse injection (at least 20 baseline measurements were taken on each trial). After application of acetylcholine, the decrease in amplitude takes about $4 \mathrm{~s}$ to reach full magnitude, and amplitude returns to the level before application of acetylcholine after about $17 \mathrm{~s}$. B: time course of amplitude change after pressure pulse applications of 3 different durations in the dentate gyrus $(15,25$, and $50 \mathrm{~ms})$. The minimum amplitude is reached after about $4 \mathrm{~s}$, but recovery takes almost $60 \mathrm{~s}$.

\section{Dual exponential equation:}

$$
W(t)=\mathrm{B}-z\left(\frac{\tau_{2} * \tau_{1}}{\tau_{2}-\tau_{1}}\right)\left(e^{\left.-t / \tau_{2}-e^{-t / \tau_{1}}\right)}\right.
$$

\section{Curve fitting to experimental data:}

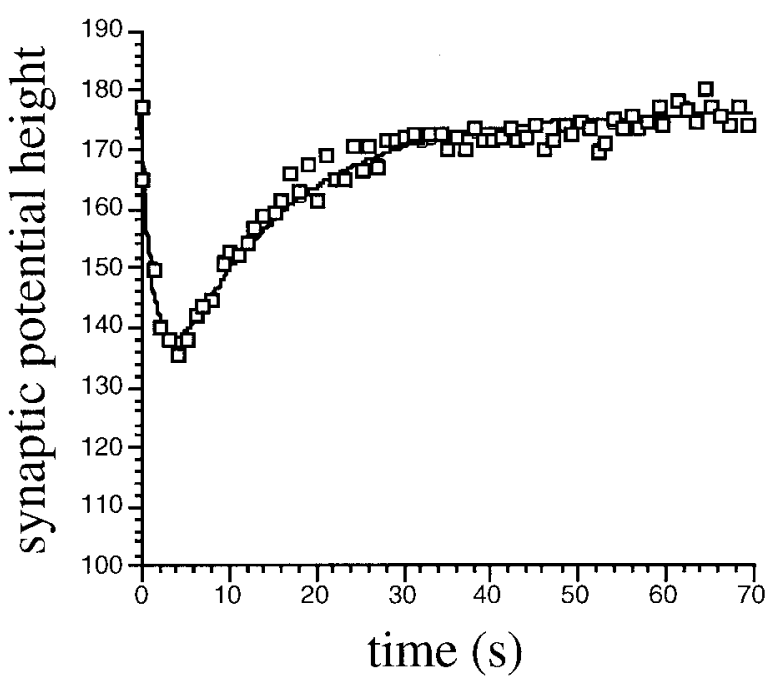

FIG. 4. Example of fitting of a dual exponential curve to physiological data (squares). Experimental data shows change in amplitude of synaptic potentials recorded in stratum radiatum of region CA1 starting immediately after pressure pulse application of acetylcholine (100-ms pulse application of $10 \mathrm{mM} \mathrm{ACh}$ at $10 \mathrm{psi}$ ). Constants for the dual exponential curve are as follows: $B=176, z=$ $31.9, \tau_{1}=1.59 \mathrm{~s}, \tau_{2}=13.3 \mathrm{~s}$.

tude. Control amplitude was measured as the average of 20 or more potentials recorded before pressure pulse application of acetylcholine or GABA. The time course of field potential amplitude changes was used to quantify the time course of modulation, as described below.

\section{Quantification of modulatory time course}

The onset and decay of modulatory effects on field potential amplitude was quantified by fitting data to dual exponential equations, using the curve fitting function in DeltaGraph Pro3. An example of curve fitting is shown in Fig. 4. Dual exponential equations have been used to effectively model the time course of synaptic potentials (Otis et al. 1993; Wilson and Bower 1992), but here we use them to model the time course of modulatory influences on synaptic potentials (not the synaptic potentials themselves). This provides an effective mathematical model useful for curve fitting. Although the dual exponential clearly does not capture all the complexities of diffusion of transmitter, activation of postsynaptic receptors, and activation of postsynaptic second-messenger pathways, it allows changes in potentials to be characterized by two time constants: an onset time constant, largely determining the onset time of the change; and a decay time constant, largely determining the speed of return to baseline. Although the time course of change in amplitude of synaptic potentials due to pressure pulse application of a modulator is longer than the time course of voltage change within a single synaptic potential, the shape of this time course is similar. We found it useful to quantify our data using this equation.

The following dual exponential equation was used to fit the data sets

$$
W(t)=B-z\left(\frac{\tau_{2} * \tau_{1}}{\tau_{2}-\tau_{1}}\right)\left(e^{-t / \tau_{2}}-e^{-t / \tau_{1}}\right)
$$


where $W(t)$ is the potential height as a function of time $(t) . B$ is the baseline amplitude of synaptic potentials, representing both initial value and eventual asymptotic value of the dual exponential equation. For the curve fittings, this constant was "the control potential height," described above. This was the only constant that was determined before the curve fitting. (This constant used the raw amplitude measurements and was used to normalize the data for plotting relative to the baseline value.) The other three constants were determined using a curve-fitting process in DeltaGraph on a PowerMac 7200. $z$ is a constant used as a scaling factor proportional to the magnitude of suppression. $\tau_{1}$ is the measured onset time constant. This constant measures the relative speed of onset of the effect. $\tau_{2}$ is the measured decay time constant. This constant measures the speed at which the effect decays.

Figure 4 shows an example of curve fitting to physiological data. The baseline was set before curve fitting, and the other constants were determined through an iterative procedure. The dual exponential model appears to fit this example data set very accurately, although the minimum of the dual exponential occurs slightly before the minimum of the physiological data set.

\section{RE S U L T S}

\section{Time course of cholinergic suppression}

Pressure pulse application of acetylcholine caused transient decreases in the amplitude of field potentials recorded in stratum radiatum of region $\mathrm{CA} 1$ and stratum moleculare of the dentate gyrus. The maximum decreases in amplitude ranged from 11 to $63 \%$, with longer pulse applications causing stronger suppression in most cases. Examples of the change in size of synaptic potentials are shown in Fig. 2. The magnitude of the changes, and the shape of the field potentials were similar to those obtained in experiments using bath application of acetylcholine or the cholinergic agonist carbachol (Hasselmo and Bower 1992; Hasselmo and Schnell 1994; Hasselmo et al. 1995; Hounsgaard 1978; Valentino and Dingledine 1981). However, the time course of these changes was considerably more rapid than those observed with bath application.

The effect on synaptic field potentials was quantified by measuring the maximum amplitude of each synaptic potential. This provided measurements at 1-s intervals, as shown in Fig. 3. Each field potential amplitude is measured relative to the height of the baseline potentials before pressure pulse injection. The height of the field potential was measured at a time point chosen to lie near the maximum amplitude. The same time point afer stimulation was used for all potentials recorded. In this example, pulses that were administered before pressure pulse application of acetylcholine are shown to the left of the axis. After application of acetylcholine, the amplitude decreases to its minimum size over several seconds, then starts to recover back to baseline. The potential reaches baseline size again in about $20 \mathrm{~s}$.

The onset and decay of the change in amplitude of synaptic field potentials showed a time course resembling that of a dual exponential. To quantify the onset and decay of modulation of synaptic potentials, all the time courses for the acetylcholine and GABA effects were fitted to dual exponential curves, as described in METHODS. An example of the dual exponential curve fit to data from a single experiment is shown in Fig. 4. While there was some variation in the shape of the time course for different experiments, this curve fitting always stayed within $5 \%$ of the change in amplitude and provided a useful quantification of the speed of onset and decay of modulatory effects.

Fitting to dual exponential curves provided measures of the average onset and decay time constant of the cholinergic modulation of synaptic potential amplitude in region CA1 and the dentate gyrus, as shown in Table 1 . The cholinergic modulation of synaptic potentials in region CA1 showed an average onset time constant $\left(\tau_{1}\right)$ of $1.96 \pm 0.27$ (mean $\pm \mathrm{SE}$ ). The average decay time constant of the modulatory effect $\left(\tau_{2}\right)$ was $13.2 \pm$ 1.74. These values were obtained from 12 slices using $100-\mathrm{ms}$ injections of $10 \mathrm{mM}$ acetylcholine at 10 psi into region CA1. With a 50-ms pressure pulse duration in region CA1, the onset time constant was $1.47 \pm 0.17$, and the decay time constant was $10.0 \pm 2.24$. The cholinergic modulation of synaptic potentials in the dentate gyrus showed an average onset time constant time constant $\left(\tau_{1}\right)$ of $1.35 \pm 0.13$. The average decay time constant of the modulatory effect $\left(\tau_{2}\right)$ was $20.4 \pm 1.36$. These values were obtained from 18 slices using 100 -ms injections of $10 \mathrm{mM}$ acetylcholine at $10 \mathrm{psi}$ into the dentate gyrus. Data were also obtained with shorter duration pressure pulse applications in the dentate gyrus. Using 50-ms injections of $10 \mathrm{mM}$ acetylcholine at $10 \mathrm{psi}$ resulted in cholinergic modulation of synaptic potentials in the dentate gyrus with an average onset time constant $\left(\tau_{1}\right)$ in nine slices of $1.16 \pm 0.17$. The average decay time constant of the modulatory effect $\left(\tau_{2}\right)$ was $19.63 \pm 1.57$. Using $25-\mathrm{ms}$ injections of $10 \mathrm{mM}$ acetylcholine at 10 psi resulted in cholinergic modulation of synaptic potentials in the dentate gyrus with an average onset time constant $\left(\tau_{1}\right)$ in eight slices of $0.728 \pm 0.16$. The average decay time constant of the modulatory effect $\left(\tau_{2}\right)$ was $20.54 \pm 1.66$. Thus smaller injections appeared to have a somewhat faster onset in the dentate gyrus, but the decay time course was not significantly different for different pressure pulse durations.

To determine whether these long decay times reflect the time course of extracellular processes or intracellular processes, separate experiments were performed in which the pressure injection of acetylcholine was followed after only $100 \mathrm{~ms}$ by pressure injections of the muscarinic antagonist atropine (1-mM concentration in pipette, $100-\mathrm{ms}$ injection duration at $10 \mathrm{psi}$ ). This would theoretically result in only a brief period of cholinergic activation of muscarinic receptors, after which

TABLE 1. Time constants of onset and decay for ACh and GABA

\begin{tabular}{cllrr}
\hline Pulse Duration & Region & Onset/Decay & \multicolumn{1}{c}{ ACh } & \multicolumn{1}{c}{ GABA } \\
\hline $25 \mathrm{~ms}$ & Dentate & Onset & $0.72 \pm 0.16$ & $0.36 \pm 0.09$ \\
$25 \mathrm{~ms}$ & Dentate & Decay & $20.53 \pm 1.66$ & $2.24 \pm 0.59$ \\
$50 \mathrm{~ms}$ & Dentate & Onset & $1.16 \pm 0.17$ & $0.29 \pm 0.05$ \\
$50 \mathrm{~ms}$ & Dentate & Decay & $19.63 \pm 1.57$ & $3.19 \pm 0.22$ \\
$50 \mathrm{~ms}$ & CA1 & Onset & $1.47 \pm 0.17$ & $0.50 \pm 0.05$ \\
$50 \mathrm{~ms}$ & CA1 & Decay & $10.00 \pm 2.24$ & $4.73 \pm 1.40$ \\
$100 \mathrm{~ms}$ & CA1 & Onset & $1.96 \pm 0.27$ & $0.67 \pm 0.15$ \\
$100 \mathrm{~ms}$ & CA1 & Decay & $13.21 \pm 1.74$ & $11.58 \pm 2.90$ \\
\hline
\end{tabular}

Values in ACh and GABA are means \pm SE. This table lists the values for the average onset time constants and decay time constants for the effects of acetylcholine (ACh) and gamma-aminobutyric acid (GABA) in different regions (region CA1 or dentate gyrus) at different pressure pulse durations (25, 50 , or $100 \mathrm{~ms}$ ). Note that for all durations of pressure pulse applications, the decay of acetylcholine effects (ACh decay) is very slow. In contrast, the time course of decay of GABA effects (GABA decay) is very short for brief pressure pulse applications and only becomes comparable to the decay of acetylcholine effects after application of GABA with $100-\mathrm{ms}$ pressure pulses in region CA1. 
atropine, with its greater potency, would block most muscarinic receptors, ensuring that the decay time constant would reflect primarily intracellular second-messenger pathways, rather than extracellular processes decreasing acetylcholine at the receptor site.

As shown in Fig. 5, pressure pulse injections of atropine at
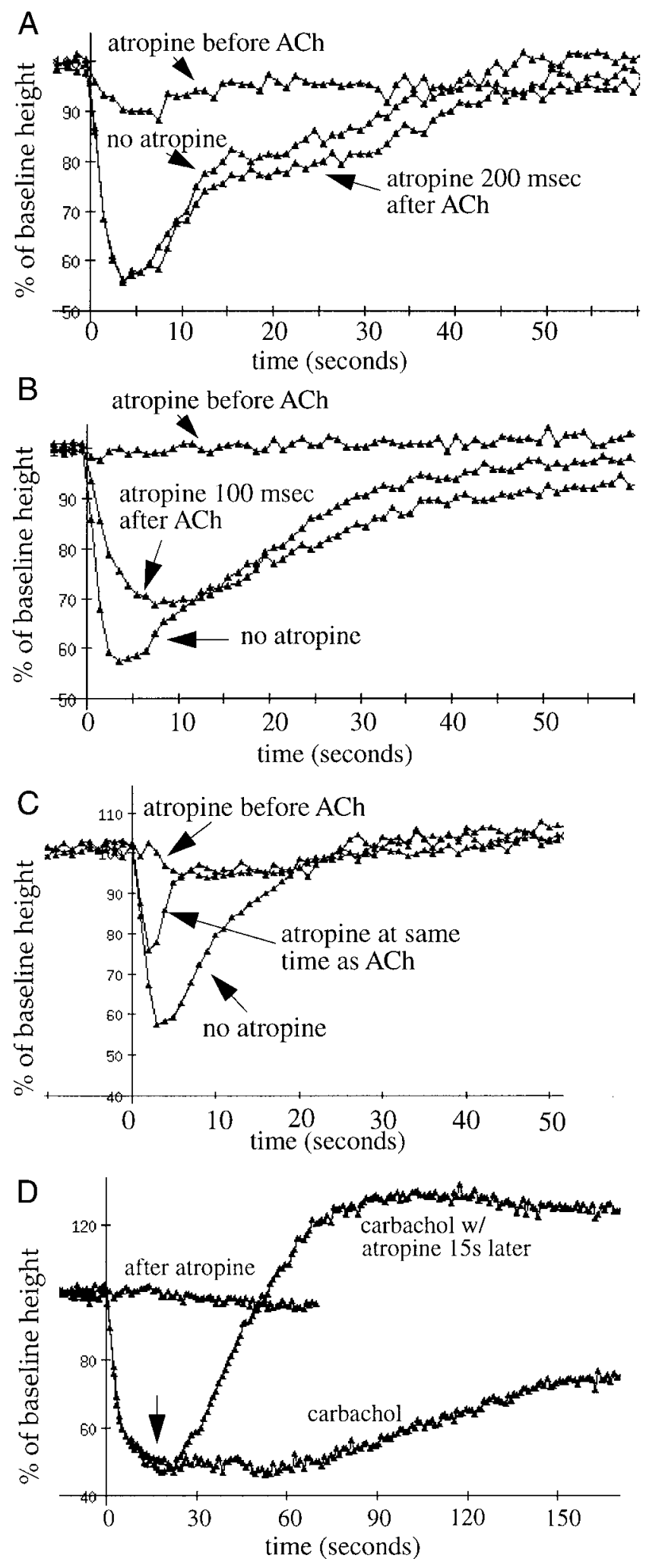

very short intervals following the injection of acetylcholine did not dramatically change the decay time course of muscarinic effects, whereas atropine injected at the same time or seconds before acetylcholine blocked most of the acetylcholine effect. In most of the six slices studied, atropine caused only a slightly shorter decay time course when injected more than $100 \mathrm{~ms}$ after acetylcholine injection in region CA1. In these experiments, acetylcholine alone caused an average onset time constant of $1.73 \pm 0.19(n=6)$ and a decay time constant of $14.9 \pm 1.6$. Acetylcholine followed by atropine at intervals between 100 and $500 \mathrm{~ms}$ later caused suppression with an average onset time constant of $2.64 \pm 0.51(n=6)$ and a decay time constant of $12.0 \pm 2.4$. Thus even when atropine followed acetylcholine by only 100 or $200 \mathrm{~ms}$, the suppression showed a slow onset over several seconds and showed a very slow decay lasting over $10 \mathrm{~s}$, as shown in Fig. 5, $A$ and $B$. This suggests that the muscarinic effects persisted intracellularly despite blockade of the effects at the muscarinic receptor (note that the time course of the acetylcholine effects suggest that the pharmacological agent reached its peak concentration at the receptor at times less than $2 \mathrm{~s}$ ). This provides a notion of the magnitude of decay time constants independent of the time course of extracellular diffusion or enzymatic degradation of acetylcholine, although the potential remains that these slow time courses are due to saturation of intracellular regulatory mechanisms.

In contrast to the lack of significant effects of atropine injections on acetylcholine effects at $>100$-ms delay, injection of atropine at the same time as acetylcholine (0-ms delay) caused a significant decrease in suppression, as shown in Fig. $5 C$. This suggests that when injected at the same time, atropine significantly interferes with the initial activation of muscarinic receptors, but when injected $100 \mathrm{~ms}$ after acetylcholine, atropine allows a brief period of muscarinic receptor activation that is sufficient to cause a large and sustained suppression of synaptic transmission. Effective blockade of muscarinic receptors by atropine is further demonstrated by the fact that after the pressure pulse injections of atropine additional application of acetylcholine had little or no effect on the synaptic poten-

FIG. 5. A: time course of suppression caused by 1) 100 -ms injection of acetylcholine alone, 2) 100-ms injection of acetylcholine followed $200 \mathrm{~ms}$ later by $100-\mathrm{ms}$ injection of atropine, and 3) another 100-ms injection of acetylcholine after the trial during which atropine was injected. Note that atropine has little effect on the cholinergic suppression induced $200 \mathrm{~ms}$ previously, while almost completely blocking any cholinergic suppression by a subsequent injection of acetylcholine. This suggests that the slow time course of acetylcholine effects is due to slow intracellular second-messenger dynamics. $B$ : time course of suppression caused by $100-\mathrm{ms}$ injection of acetylcholine before atropine, with atropine injection at $100 \mathrm{~ms}$, and subsequent to the trial with atropine. Again, atropine completely blocks the effect of a subsequent presentation of acetylcholine, but not the effect at $100 \mathrm{~ms}$. C: time course of suppression induced by 1) 100-ms injection of acetylcholine alone, 2) 100-ms injection of acetylcholine at exactly the same time as 100-ms injection of atropine (0-ms delay), and 3) another 100-ms injection of acetylcholine after atropine. Note that atropine prevents most of the suppression when injection at 0 delay, as opposed to its lack of a strong effect when injected 100 or $200 \mathrm{~ms}$ later as shown in $A$ and $B . D$ : time course of suppression by caused by 1 ) 100-ms injection of carbachol alone, 2) 100-ms injection of carbachol followed $15 \mathrm{~s}$ later by $100-\mathrm{ms}$ injection of atropine, and 3) another 100-ms injection of carbachol after atropine. Note that atropine after carbachol allows a slow recovery to a level above baseline, preventing the normal prolonged effect of carbachol. It appears that the time course of this slow change reflects the time course of intracellular changes induced by atropine's blockade of the sustained activation of muscarinic receptors by atropine. 
tials, showing that even long after it was injected atropine was more effective at binding to muscarinic receptors than was acetylcholine. In the dentate gyrus, injections of atropine at short time intervals did cause a somewhat faster decay time constant.

The sustained effect of carbachol injections provided another means of observing the slow decay of intracellular processes initiated by muscarinic receptor activation. Carbachol is not hydrolyzed by acetylcholinesterase, and therefore pressure injections of carbachol cause a long sustained suppression reflecting the time course of carbachol diffusion alone. As shown in Fig. 5D, a $100-\mathrm{ms}$ injection of atropine $15 \mathrm{~s}$ after carbachol injection brings the potential up above baseline more rapidly, but the recovery does not start until $5 \mathrm{~s}$ after atropine injection and once started still takes over $25 \mathrm{~s}$. This appears to reflect the slow recovery to baseline of intracellular secondmessenger processes that were activated by carbachol and received no further activation after injection of atropine. Another injection of carbachol after atropine has no suppressive effect at all.

\section{Time course of GABAergic modulation of synaptic potentials}

Pressure pulse applications of GABA caused more rapid transient decreases in the amplitude of field potentials recorded in stratum radiatum of region CA1 and stratum moleculare of the dentate gyrus. Both the onset and recovery of the decreases caused by GABA were more rapid than the onset and recovery after applications of ACh. The maximum decreases in amplitude ranged from 21.3 to $70.7 \%$, and longer pulse applications again caused stronger suppression. Examples of the change in size of synaptic potentials are shown in Fig. 6.

The time course of GABA effects on field potentials were measured at 1-s intervals and also at much shorter intervals. An example of the effects of GABA measured at 1-s intervals in the dentate gyrus is shown in Fig. 7. This example shows the change in synaptic potential height for three different lengths

\section{A GABA in Region CA1}
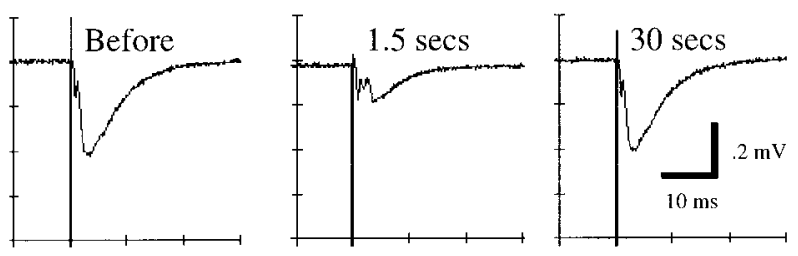

\section{B GABA in dentate gyrus}
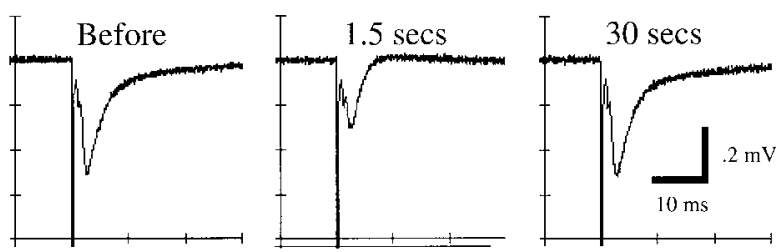

FIG. 6. A: example of the effect of pressure pulse application of GABA on synaptic potentials recorded in stratum radiatum of hippocampal region CA1. Potentials are shown before injection, $1.5 \mathrm{~s}$ after pressure pulse application of $\mathrm{GABA}$, and $30 \mathrm{~s}$ after pressure pulse application of GABA. B: effect of pressure pulse application of GABA on synaptic potentials recorded in stratum moleculare of the dentate gyrus before application, $1.5 \mathrm{~s}$ after application, and $30 \mathrm{~s}$ after application.

\section{GABA in dentate gyrus}

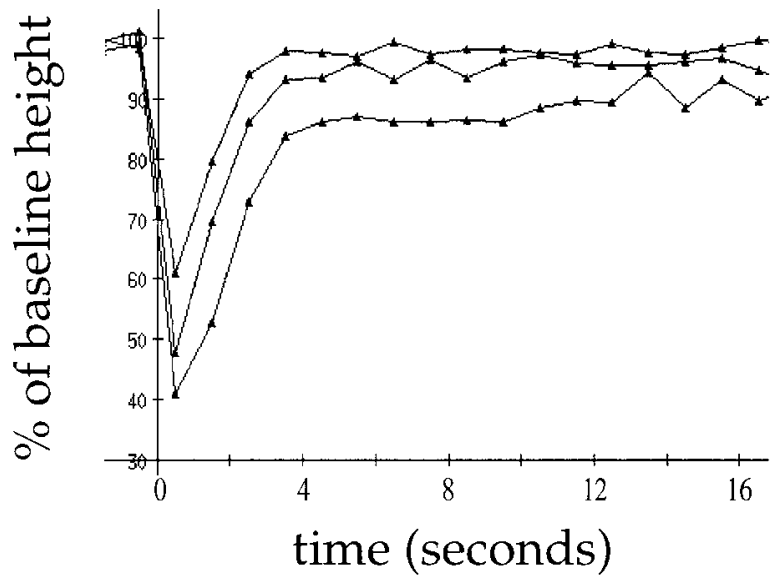

FIG. 7. Time course of change in height of synaptic potentials plotted at 1-s intervals after pressure pulse application of GABA to stratum moleculare of the dentate gyrus. The time courses of change in synaptic potentials are shown after 3 different durations of pressure pulse application (10,25, and $50 \mathrm{~ms}$, all with 5-mM concentrations of GABA in the pipette). An increased duration of pressure pulse application increased the maximum suppression of field potential, while the time course of suppression remained relatively similar.

of pressure pulse application: 10,25 , and $50 \mathrm{~ms}$. Note that the maximum effect has been reached after $1 \mathrm{~s}$ in this example, and the maximum increases with length of pressure pulse application. Most of the effect has decayed by $4 \mathrm{~s}$ after the time of pressure pulse application.

Because of the rapid onset of suppression after pressure pulse injections of GABA, it was necessary to analyze the time course of this effect with a higher temporal resolution. This was accomplished by varying the time between the pressure pulse application and the first stimulation of a synaptic potential by 100-ms steps. (In contrast, in the previous experiments the time between pressure pulse application and stimulation of the 1 st synaptic potential was always $500 \mathrm{~ms}$.) For these high-resolution examples, measurements were made at 10, 20, $30,50,100,200,300$, and $500 \mathrm{~ms}$, then continued at 500-ms intervals up to $3 \mathrm{~s}$.

An example of the high-resolution time course of GABA effects is shown in Fig. 8. Note that the onset of suppression of synaptic potentials after pressure pulse application of GABA is very rapid; within the first $100 \mathrm{~ms}$. However, in some cases the ejection disturbed the field potential at very short intervals. The baseline of the field potential was normally very stable, but when GABA was ejected at a time near the initiation of the field potential, this baseline and the subsequent potential were often disturbed. No disturbance was noted for time intervals $>50 \mathrm{~ms}$. In examples from the dentate gyrus (Fig. 8, top), there was no clear disturbance of field potential, but the depression was at 20 or $40 \%$ of maximum even after only $10 \mathrm{~ms}$. For one potential studied, maximum suppression was obtained near 300 ms. Note that onset and decay of the effect of GABA were more rapid in experiments on the dentate gyrus than in region CA1 (Fig. 8, bottom).

The rapid time course shown in Fig. 8 is supported by the average data obtained for different durations of pressure pulse injections of GABA. Values were obtained in region CA1 from four slices with 100 -ms injections of 5 or $10 \mathrm{mM}$ GABA at 10 psi. In this case, the depression of synaptic potentials showed 
Onset of GABA suppression of synaptic potentials in the dentate gyrus

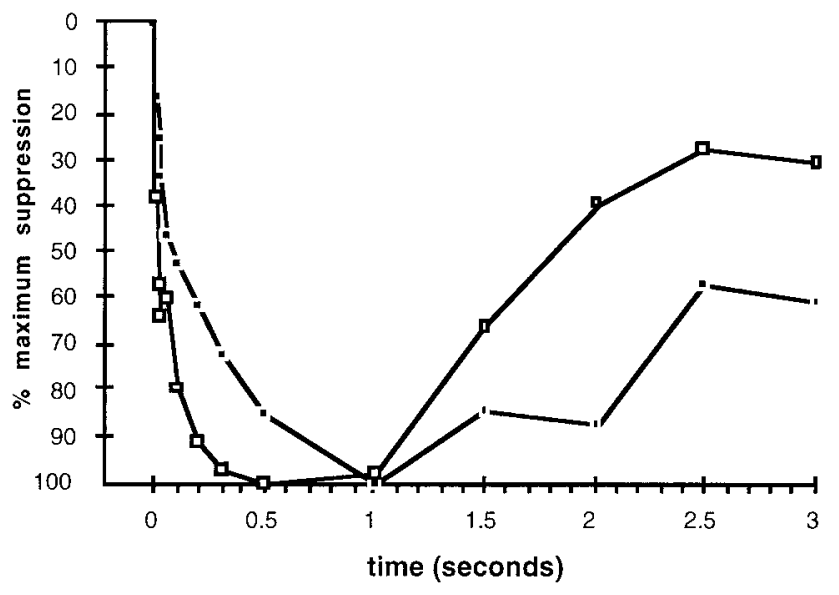

Onset of GABA suppression of synaptic potentials in region $\mathrm{CA} 1$

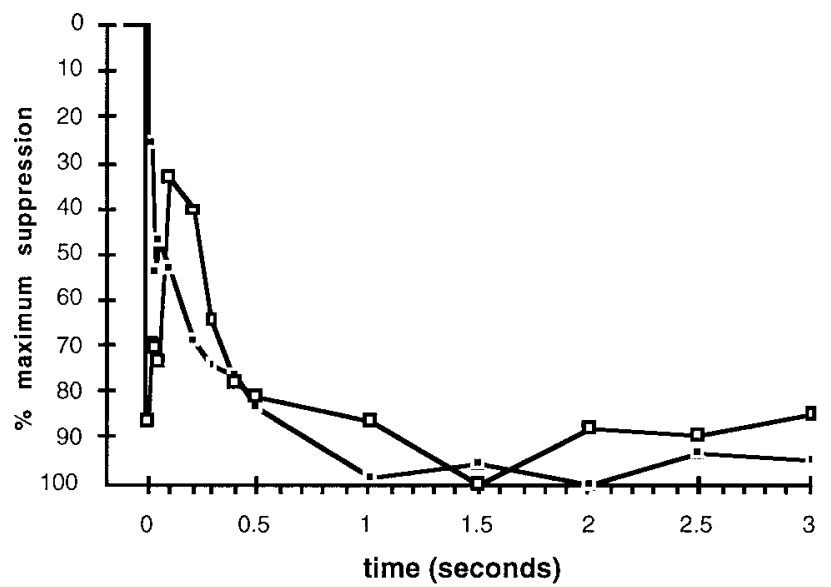

FIG. 8. Time course of depression after GABA injection measured at higher resolution $(10,20,30,50,100,200,300$, and $500 \mathrm{~ms})$ for 1$) 2$ examples in stratum moleculare of dentate gyrus and 2) 2 examples in stratum radiatum of region CA1. Before the injection of GABA, the synaptic potentials were at baseline magnitude ( $0 \%$ maximum suppression). These graphs show the onset of suppression (the downward curve toward maximum suppression) and partial recovery back up toward baseline. Note that $100 \%$ maximum suppression corresponds to the largest suppression for that particular case (which was never a total suppression). The strong suppression at intervals $<50 \mathrm{~ms}$ for one of the traces in region CA1 is probably caused by mechanical disturbances from the pressure pulse injection.

an onset time constant $\left(\tau_{1}\right)$ of $0.667 \pm 0.15$ (mean \pm SE). The average decay time constant of the modulatory effect $\left(\tau_{2}\right)$ was $11.6 \pm 2.9(n=4)$. Shorter injections in region CA1 were also performed. Fifty-millisecond injections into region CA1 in nine slices resulted in an average onset time $\left(\tau_{1}\right)$ of $0.502 \pm$ 0.05 , and the average decay time constant of the modulatory effect $\left(\tau_{2}\right)$ was $4.73 \pm 1.4$. The decay time constant was much faster in the dentate gyrus. With 50-ms injections, the effect on synaptic potentials in the dentate gyrus (5 slices) showed an average onset time constant $\left(\tau_{1}\right)$ of $0.297 \pm 0.053$, and the average decay time constant of the modulatory effect $\left(\tau_{2}\right)$ was $3.19 \pm 0.219$. Using 25 -ms injections in four slices, the depression of synaptic potentials in the dentate gyrus showed an average onset time constant $\left(\tau_{1}\right)$ of $0.369 \pm 0.09$ and an average decay time constant $\left(\tau_{2}\right)$ of $2.24 \pm 0.59$. Using 10-ms injections in five slices, the depression of synaptic potentials in the dentate gyrus showed an average onset time constant $\left(\tau_{1}\right)$ of $0.367 \pm 0.084$ and an average decay time constant $\left(\tau_{2}\right)$ of $1.73 \pm 0.377$. For GABA, shorter duration pressure pulse applications resulted in a somewhat slower onset time constant, but a faster decay time constant. This faster decay time constant with shorter durations contrasts with the long decay time constants for all durations of acetylcholine injections. The time course of GABA effects were consistently faster than the time course of ACh effects in slices, as can be seen in Table 1.

To investigate the receptor subtype involved in this suppression of synaptic potentials, we infused the slice chamber with the $\mathrm{GABA}_{\mathrm{A}}$ antagonist bicuculline and tested the effect of GABA. The suppression of synaptic potentials by GABA was unaffected by bicuculline in some cases and showed a partial reduction in the presence of $10 \mu \mathrm{M}$ bicuculline in others, but it was not possible to obtain complete blockade of the effect by bicuculline. We tested the $\mathrm{GABA}_{\mathrm{B}}$ agonist baclofen and found a strong sustained suppression, even with the same short pressure pulse parameters used to obtain the rapid GABA effect. This sustained suppression probably resulted from the absence of specific reuptake or degradation mechanisms for this artificial agonist. As shown in Fig. 9, a single application of baclofen causes over 2 min worth of suppression. Pressure pulse application of phaclofen causes a moderately rapid but partial release of this suppression.

\section{I S C U S S I O N}

These results demonstrate the relative time course of cholinergic and GABAergic effects on synaptic potentials in hippocampal region $\mathrm{CA} 1$ and the dentate gyrus. The cholinergic modulation of synaptic transmission appears to have a consistently slower onset and more sustained duration than the effects of GABA. Acetylcholine effects persisted for extended periods $(10-20 \mathrm{~s})$ regardless of the duration of the pressure pulse application (25-100 ms), and even after further receptor activation was blocked by a pressure pulse application of atropine $100 \mathrm{~ms}$ after acetylcholine application. This suggests that the intracellular second-messenger pathways activated by acetylcholine have an extended period of persistence even after a brief period of muscarinic receptor activation.

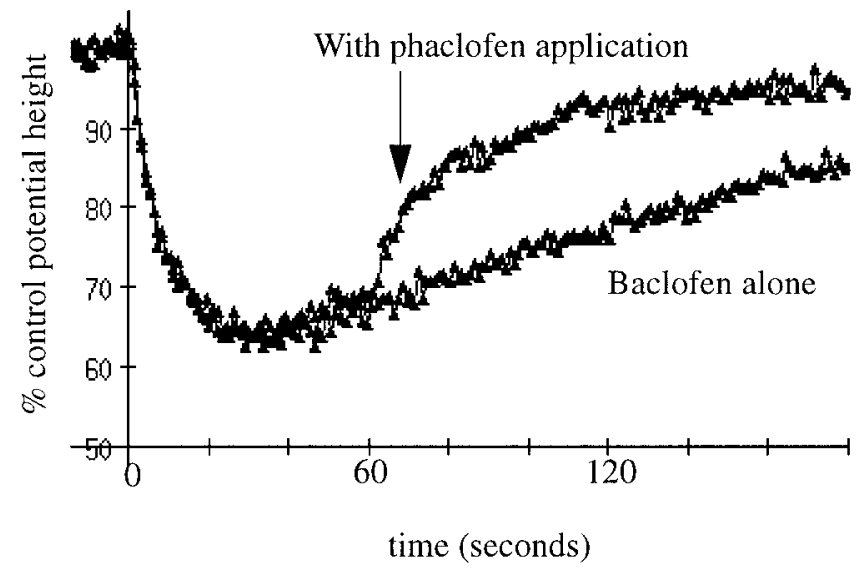

FIG. 9. Suppression of synaptic transmission caused by a single 25-ms pressure pulse application of $1 \mathrm{mM}$ baclofen at time 0 . Note the long, sustained effect due to absence of endogenous uptake mechanisms for baclofen. In a separate trial, pressure pulse application of phaclofen $(500 \mathrm{~ms}, 10 \mathrm{mM})$ after $60 \mathrm{~s}$ causes partial release of the suppression by baclofen. 
The relatively slow time course of muscarinic cholinergic modulation appears consistent with the slow time course of the depolarization of pyramidal cells by activation of muscarinic cholinergic receptors (Benardo and Prince 1982; Cole and Nicoll 1984). These data suggest that despite the rhythmic firing of cholinergic neurons during theta rhythm (Brazhnik and Fox 1997, 1999) the release of acetylcholine causes a relatively slow tonic change in muscarinic receptor effects on synaptic transmission and postsynaptic depolarization. This could mediate tonic changes in network dynamics as levels of acetylcholine change during different stages of waking and sleep (see Hasselmo 1999 for review).

In contrast, the effects of GABA on synaptic transmission show a significantly faster onset and shorter duration than acetylcholine at all pressure pulse durations. In addition, the time course of onset and decay of GABA effects becomes more rapid with briefer pressure pulse durations, reducing to values of decay around $2 \mathrm{~s}$ for 10 - and 25 -ms pressure pulse durations. These results suggest that the presynaptic inhibition of synaptic transmission may function on different time scales, with muscarinic cholinergic effects showing a slower onset and longer persistence than the faster and less persistent effects of GABAergic modulation at $\mathrm{GABA}_{\mathrm{B}}$ receptors.

This evidence for faster effects at $\mathrm{GABA}_{\mathrm{B}}$ receptors is consistent with other data from this laboratory on heterosynaptic depression due to activation of $\mathrm{GABA}_{\mathrm{B}}$ receptors in vivo (B. J. Molyneaux and M. E. Hasselmo, unpublished observations). In that study, synaptic potentials in stratum radiatum of region CA1 evoked by contralateral stimulation showed heterosynaptic depression due to ipsilateral stimulation preceding the contralateral stimulation. This heterosynaptic depression had a total time course $<300 \mathrm{~ms}$ and was decreased by a $\mathrm{GABA}_{\mathrm{B}}$ receptor antagonist. The slower time course observed in the in vitro experiments presented here may result from differences in the time course of GABA diffusion, reuptake and intracellular second-messenger processes activated by $\mathrm{GABA}_{\mathrm{B}}$ receptors in vitro versus in vivo. The time course observed here with brief (10-25 ms) pressure pulse applications of GABA resembles the time course of heterosynaptic depression observed in studies of heterosynaptic depression in slice preparations of hippocampal region CA1 (Isaacson et al. 1993) and the cerebellum (Dittman and Regehr 1997), and in studies of homosynaptic depression of inhibitory transmission in slice preparations (Lambert and Wilson 1994; Otis et al. 1993). The course of $\mathrm{GABA}_{\mathrm{B}}$ modulation of synaptic transmission was proposed to be much more rapid at physiological temperatures in vivo (Dittman and Regehr 1997). The homosynaptic depression of inhibitory transmission could contribute to the enhancement of long-term potentiation caused by $\mathrm{GABA}_{\mathrm{B}}$ receptors in some conditions (Mott and Lewis 1991, 1994; Mott et al. 1990, 1993).

The suppression of glutamatergic synaptic transmission by activation of muscarinic and $\mathrm{GABA}_{\mathrm{B}}$ receptors appears to involve a decrease in calcium influx through presynaptic voltage-dependent calcium channels (VDCC) (Pfrieger et al. 1994; Qian and Saggau 1997; Wu and Saggau 1995, 1997). In particular, these effects seem to involve the type of VDCC sensitive to the omega-conotoxin GVIA (omega-CgTXGVIA), which is also known as the N-type current. The effect on presynaptic calcium influx was reported to have a similar time course for activation of muscarinic and $\mathrm{GABA}_{\mathrm{B}}$ receptors
(Wu and Saggau 1997), but those experiments used carbachol to activate muscarinic receptors and baclofen to activate $\mathrm{GABA}_{\mathrm{B}}$ receptors. As can be seen in the data presented here, both baclofen and carbachol have a slow time course of effects due to the lack of reuptake or breakdown mechanisms regulating the extracellular concentrations of these substances. The differences in time course observed here could involve the different components of the signaling pathways activated by these receptors. Muscarinic receptors activate phospholipase $\mathrm{C}$ via a G-protein-coupled mechanism (Schobesberger et al. 2000). Phospholipase C increases levels of inositol triphosphate (which influences intracellular calcium concentrations) and diacylglycerol (which activates protein kinase C). The time courses observed here could result from the specific kinetics of these signaling pathways in neurons. The $\mathrm{GABA}_{\mathrm{B}}$ receptor appears to act through mechanisms of inhibiting adenylate cyclase, and its time course will be better understood when the detailed kinetics of its signaling pathways are analyzed.

\section{Functional implications}

These different time courses of the cholinergic and GABAergic modulation of synaptic transmission could underlie different functional roles for the two types of modulation. The slower effects at muscarinic cholinergic receptors have been proposed to underlie a slower shift of hippocampal dynamics from encoding, with a dominant influence of feedforward, afferent input, to consolidation, with a dominant influence of feedback transmission (Hasselmo 1999). This would provide a pharmacological regulation of the dynamics described in previous theories of the two-stage formation of memories (Buzsaki 1989). In this framework, during active waking, high levels of acetylcholine (Marrosu et al. 1995) would suppress excitatory feedback in region CA3 and from region CA3 to region $\mathrm{CA} 1$, preventing representations previously encoded in the hippocampus from interfering with new encoding (Hasselmo 1999; Hasselmo and Schnell 1994). Then, as levels of acetylcholine decrease during quiet waking or slow-wave sleep, the slow decrease in muscarinic suppression of synaptic transmission would allow a shift into dynamics dominated by strong excitatory synaptic connections. The increase in strength of excitatory transmission could underlie the occurrence of brief explosive increases in network activity termed "sharp waves" in region CA3, which then spread from region CA3 to region CA1 and back to entorhinal cortex (Buzsaki 1989; Chrobak and Buzsaki 1994). Activity during these sharp waves could be influenced by connections strengthened in the hippocampus during previous encoding phases, so that sharp wave activity could alter neocortical representations on the basis of hippocampal connectivity (Buzsaki 1989; Chrobak and Buzsaki 1994; Hasselmo 1999; Wilson and McNaughton 1994). The slow change in muscarinic effects between different states would prevent sharp waves from intruding during encoding.

In contrast to the slower effects of cholinergic modulation, the more rapid modulation of synaptic transmission by activation of $\mathrm{GABA}_{\mathrm{B}}$ receptors could allow a more rapid shift in dynamics within each cycle of the theta rhythm. This is supported by the in vivo data showing that heterosynaptic depression has a time course fast enough to fit within each cycle of the theta rhythm (Molyneaux and Hasselmo, unpublished ob- 
servations), and showing cyclical changes in magnitude of synaptic transmission at different phases of the theta cycle (Ruddell and Fox 1984; Ruddell et al. 1980; Wyble et al. 2000). Phasic changes during each theta cycle could allow rapid shifting between dynamics appropriate for encoding, with a dominant influence of feed-forward afferent input, and retrieval, with a dominant influence of feedback synaptic transmission (Hasselmo et al. 2001). During encoding, $\mathrm{GABA}_{\mathrm{B}}$ suppression of feedback excitatory connections and the Schaffer collaterals in region CA1 would prevent previously encoded representations activated during retrieval from being encoded as new (Hasselmo et al. 2001; Sohal and Hasselmo 1998a,b; Wallenstein and Hasselmo 1997). If transmission must be suppressed to prevent interference during synaptic modification, this provides a functional rationale explaining why the same $\mathrm{GABA}_{\mathrm{B}}$ receptors that suppress excitatory transmission in stratum radiatum (Ault and Nadler 1982; Colbert and Levy 1992) also enhance long-term potentiation at these same synapses (Mott and Lewis 1991, 1994). In the phase when $\mathrm{GABA}_{\mathrm{B}}$ suppression is weaker, excitatory feedback synaptic transmission will be strong, and dynamics of retrieval would dominate within hippocampal circuits. The rapid shift in strength of excitatory feedback connections could be important for preventing confusion between network activation due to external reality and activation due to internal retrieval.

We appreciate the assistance of Dr. Madhvi Patil in setting up these experiments.

This research was supported by National Institute of Mental Health Grants MH-60013 and MH-61492 and by National Science Foundation Grant IBN9996177.

\section{REFERENCES}

Ault B AND NADLER JV. Baclofen selectively inhibits transmission at synapses made by axons of CA3 pyramidal cells in the hippocampal slice. $J$ Pharmacol Exp Ther 223: 291-297, 1982.

BENARDO LS. Characterization of cholinergic and noradrenergic slow excitatory postsynaptic potentials from rat cerebral cortical neurons. Neuroscience 53: 11-22, 1993.

BenaRdo LS AND PRINCE DA. Ionic of cholinergic excitation in mammalian hippocampal pyramidal cells. Brain Res 249: 333-344, 1982.

BLAND BH AND COLOM LV. Extrinsic and intrinsic properties underlying oscillation and synchrony in limbic cortex. Prog Neurobiol 41: 157-208, 1993

BRAZHNIK ES AND Fox SE. Intracellular recordings from medial septal neurons during hippocampal theta rhythm. Exp Brain Res 114: 442-453, 1997.

BRAZHNIK ES AND FOX SE. Action potentials and relations to the theta rhythm of medial septal neurons in vivo. Exp Brain Res 127: 244-258, 1999.

Brocher S, Artola A, AND Singer W. Agonists of cholinergic and noradrenergic receptors facilitate synergistically the induction of long-term potentiation in slices of rat visual cortex. Brain Res 573: 27-36, 1992.

Brucato FH, Mott DD, Lewis DV, and Swartzwelder HS. GABAB receptors modulate synaptically-evoked responses in the rat dentate gyrus, in vivo. Brain Res 677: 326-332, 1995.

BUZSAKI G. Two stage model of memory trace formation: a role for 'noisy' brain states. Neuroscience 31: 551-570, 1989.

BUZSAKI G AND EIDELBERG E. Phase-relations of hippocampal projection cells and interneurons to theta activity in the anesthetized rat. Brain Res 266: $334-339,1983$.

Chrobak JJ and BuzsaKi G. Selective activation of deep layer (V-VI) retrohippocampal cortical neurons during hippocampal sharp waves in the behaving rat. J Neurosci 14: 6160-6170, 1994

COLBERT CM AND LEVY WB. Electrophysiological and pharmacological characterization of perforant path synapses in CA1: mediation by glutamate receptors. J Neurophysiol 68: 1-7, 1992.

Cole AE AND NICOLL RA. Characterization of a slow cholinergic postsynaptic potential recorded in vitro from rat hippocampal pyramidal cells. $J$ Physiol (Lond) 352: 173-188, 1984.
Dittman JS AND Regehr WG. Mechanism and kinetics of heterosynaptic depression at a cerebellar synapse. J Neurosci 17: 9048-9059, 1997.

Fox SE, Wolfson S, AND RANCK JBJ. Hippocampal theta rhythm and the firing of neurons in walking and urethane anesthetized rats. Exp Brain Res 62: 495-508, 1986

Hasselmo ME. Neuromodulation and cortical function: modeling the physiological basis of behavior. Behav Brain Res 67: 1-27, 1995.

Hasselmo ME. Neuromodulation: acetylcholine and consolidation. Trends Cognit Sci 3: 351-359, 1999.

Hasselmo ME, Bodelón C, AND Wyble BP. A proposed function for hippocampal theta rhythm: separate phases of encoding and retrieval enhance reversal of prior learning. Neural Comput. In press.

Hasselmo ME AND Bower JM. Cholinergic suppression specific to intrinsic not afferent fiber synapses in rat piriform (olfactory) cortex. J Neurophysiol 67: 1222-1229, 1992.

Hasselmo ME AND CEKIC M. Suppression of synaptic transmission may allow combination of associative feedback and self-organizing feedforward connections in the neocortex. Behav Brain Res 79: 153-161, 1996.

Hasselmo ME And Schnell E. Laminar selectivity of the cholinergic suppression of synaptic transmission in rat hippocampal region CA1: computational modeling and brain slice physiology. J Neurosci 14: 3898-3914, 1994.

Hasselmo ME, Schnell E, AND Barkai E. Dynamics of learning and recall at excitatory recurrent synapses and cholinergic modulation in hippocampal region CA3. J Neurosci 15: 5249-5262, 1995.

HasSELmo ME, Wyble BP, AND WalLENSTEIN GV. Encoding and retrieval of episodic memories: role of cholinergic and GABAergic modulation in the hippocampus. Hippocampus 6: 693-708, 1996

Herreras O, Solis JM, Herranz AS, Martin del Rio R, and Lerma J. Sensory modulation of hippocampal transmission. II. Evidence for a cholinergic locus of inhibition in the Schaffer-CA1 synapse. Brain Res 461: 303-313, 1988.

HOUNSGAARD J. Presynaptic inhibitory action of acetylcholine in area CA1 of the hippocampus. Exp Neurol 62: 787-797, 1978.

ISAACSON JS, SOLIS JM, AND NICOLL RA. Local and diffuse synaptic actions of GABA in the hippocampus. Neuron 10: 165-175, 1993.

KAHLE JS AND COTMAN CW. Carbachol depresses the synaptic responses in the medial but not the lateral perforant path. Brain Res 482: 159-163, 1989.

LAMBERT NA AND WILSON WA. Temporally distinct mechanisms of usedependent depression at inhibitory synapses in the rat hippocampus in vitro. J Neurophysiol 72: 121-130, 1994.

Linster C, Wyble BP, AND Hasselmo ME. Electrical stimulation of the horizontal limb of the diagonal band of broca modulates population EPSPs in piriform cortex. J Neurophysiol 81: 2737-2742, 1999.

Marrosu F, Portas C, Mascia mS, Casu ma, Fa M, Giagheddu M, IMPERATO A, AND GESSA GL. Microdialysis measurement of cortical and hippocampal acetylcholine release during sleep-wake cycle in freely moving cats. Brain Res 671: 329-332, 1995.

MotT DD AND LEWIS DV. Facilitation of the induction of long-term potentiation by GABAB receptors. Science 252: 1718-1720, 1991.

MotT DD AND LEwIS DV. The pharmacology and function of central GABAB receptors. Int Rev Neurobiol 36: 97-223, 1994.

MotT DD, Lewis DV, FerRari CM, Wilson WA, AND Swartzwelder HS. Baclofen facilitates the development of long-term potentiation in the rat dentate gyrus. Neurosci Lett 113: 222-226, 1990.

Mott DD, XIE CW, Wilson WA, Swartzwelder HS, and Lewis DV. GABAB autoreceptors mediate activity-dependent disinhibition and enhance signal transmission in the dentate gyrus. J Neurophysiol 69: 674-691, 1993.

OTIS TS, DeKoninck Y, AND Mody I. Characterization of synaptically elicited GABA(B) responses using patch-clamp recordings in rat hippocampal slices. J Physiol (Lond) 463: 391-407, 1993.

Pfrieger FW, GotTMAnN K, AND Lux HD. Kinetics of GABAB receptormediated inhibition of calcium currents and excitatory synaptic transmission in hippocampal neurons in vitro. Neuron 12: 97-107, 1994.

QIAN J AND SAGGaU P. Presynaptic inhibition of synaptic transmission in the rat hippocampus by activation of muscarinic receptors: involvement of presynaptic calcium influx. Br J Pharmacol 122: 511-519, 1997.

RUDELL AP AND Fox SE. Hippocampal excitability related to the phase of the theta rhythm in urethanized rats. Brain Res 294: 350-353, 1984.

RUDELl AP, Fox SE, AND RANCK JBJ. Hippocampal excitability phase-locked to the theta rhythm in walking rats. Exp Neurol 68: 87-96, 1980. 
Schobesberger H, Wheeler DW, ANd Horn JP. A model for pleiotropic muscarinic potentiation of fast synaptic transmission. J Neurophysiol 83: 1912-1923, 2000.

Skaggs WE, McNaughton BL, Wilson MA, and Barnes CA. Theta phase precession in hippocampal neuronal populations and the compression of temporal sequences. Hippocampus 6: 149-172, 1996.

SoHAL VS AND HASSElmo ME. Changes in GABAB modulation during a theta cycle may be analogous to the fall of temperature during annealing. Neural Comput 10: 889-902, 1998a.

SoHAL VS AND HASSELmo ME. GABAB modulation improves sequence disambiguation in computational models of hippocampal region CA3. Hippocampus 8: 171-193, 1998b.

Stewart M AND Fox SE. Do septal neurons pace the hippocampal theta rhythm? Trends Neurosci 13: 163-168, 1990.

TANG AC AND Hasselmo ME. Selective suppression of intrinsic but not afferent fiber synaptic transmission by baclofen in the piriform (olfactory) cortex. Brain Res 659: 75-81, 1994.

Toth K, FREUnd TF, AND MiLES R. Disinhibition of rat hippocampal pyramidal cells by GABAergic afferent from the septum. J Physiol (Lond) 500: 463-474, 1997.

VAlentino RJ And Dingledine R. Presynaptic inhibitory effect of acetylcholine in the hippocampus. J Neurosci 1: 784-792, 1981.
Wallenstein GV and Hasselmo ME. GABAergic modulation of hippocampal activity: sequence learning, place field development, and the phase precession effect. J Neurophysiol 78: 393-408, 1997.

WiLliams SH AND Constanti A. Quantitative effects of some muscarinic agonists on evoked surface-negative field potentials recorded from the guinea-pig olfactory cortex slice. Br J Pharmacol 93: 846-854, 1988.

WILSON MA AND BOWER JM. Cortical oscillations and temporal interactions in a computer simulation of piriform cortex. J Neurophysiol 67: 981-995, 1992.

WiLson MA and McNaughton BL. Reactivation of hippocampal ensemble memories during sleep. Science 265: 676-679, 1994.

Wu LG AND SAGGAU P. GABA receptor-mediated presynaptic inhibition in guinea-pig hippocampus is caused by reduction of presynaptic $\mathrm{Ca}^{2+}$ influx. J Physiol (Lond) 485: 649-657, 1995.

Wu LG AND SAGgau P. Presynaptic inhibition of elicited neurotransmitter release. Trends Neurosci 20: 204-212, 1997.

Wyble BP, Linster C, And Hasselmo ME. Size of CA1-evoked synaptic potentials is related to theta rhythm phase in rat hippocampus. J Neurophysiol 83: 2138-2144, 2000

YAMAмото C AND KAWAI N. Presynaptic action of acetylcholine in thin sections from the guinea-pig dentate gyrus in vitro. Exp Neurol 19: 176187, 1967. 